Europe's Journal of Psychology, 7(2), pp. 295-322

www.ejop.org

How does pupils' emotional coping develop within learning situations during primary school years?

\author{
Eeva-Liisa Peltokorpi \\ University of Helsinki \\ Kaarina Määttä \\ University of Lapland
}

\begin{abstract}
Emotional coping is an emotional-based psychological process that contributes to achieving the goal of emotional regulation. As such, the development of emotional coping can be understood as an individual's inner coping process which consists of various elements. This article describes the development of children's emotional coping and the teaching methods that enhance it in the school class. A range of interactive learning activities were planned and carried out in the classroom and the measures of emotional coping were created. Nine pupils aged between seven and eight who had problems with their emotional coping were selected as the research participants. Their development and teaching were observed and the pupils' self-evaluations were collected during the study year 2006-2007 in interactional classroom situations that involved mathematical problem-solving tasks. The aim of the research was to study 1) how primary school pupils' emotional coping develops and 2) with what kind of teaching methods their emotional coping could be enhanced. Results showed that pupils' individual emotional coping can be illustrated through various mathematical reasoning and problem-solving tasks in stages. Emotional coping skills are important for individuals' success and wellbeing and the foundation for these skills can be laid already in the early years.
\end{abstract}

Keywords: emotional coping, emotional regulation, primary school, emotional intelligence, children.

Practical experiences in teaching show that, alongside the transmission of information, the school has to focus on achieving goals related to socio-emotional skills and pupils' comprehensive wellbeing more than before. It seems that 
nowadays children have difficulties to get along with their peers and friends (GiffordSmith \& Brownell, 2003; LeBlanck, Sautter, \& Dore, 2006). In addition, the amount of information transmitted in most schools is enormous and a child's mind can become exhausted by the flood of information (Rowe et al., 2010; Zullig et al., 2010). Today's curricula prefer information-oriented studying to subjects that could provide the children with experiences of recognizing and paying attention to their own self and needs. Acquiring social skills is nevertheless invaluable for the children's forthcoming life (Cheng \& Furnham, 2002; Woodward \& Fergusson, 2000). Does today's school emphasize the transmission of information, which seems to be valued the most by the society, at the expense of emotional life (Uusikylä, 2005, p. 25)? Should we also study the skills of living along with the academic skills at school?

This article leans especially on the theories of emotional regulation (Brenner \& Salovey, 1997), Boekaerts' (1996) theory of coping process and the classification of emotional coping developed by Eisenberg's research group (1993). This article studies the development of pupils' emotional coping and the kind of teaching solutions that can enhance interactional learning situations in the classroom. The aim of this article is to increase our understanding concerning children's emotional coping and to support teachers' work on enhancing children's readiness to handle challenging social situations at school.

\section{What is emotional coping?}

According to Matthews et al. (2000), emotional coping is the ability to handle various demands. They define the concept briefly but the definition can be interpreted in several ways. Based on their description, emotional coping can be understood as a skill or ability that can be taught. Additionally, according to the definition, emotional coping can be interpreted as the ability to handle difficult situations in life. This assumption is supported by Brenner and Salovey's (1997) definition of emotional coping. They consider emotional coping as a process in which a child uses previously learned coping skills in difficult problem situations. Boekaerts (1996) shares this opinion but emphasizes the strong influence of individuals' emotions and their assessment to the selection of a particular coping method. Boekaerts has developed a model of the coping process to makes the concept of emotional coping operational. According to this model, people use emotions to enhance their wellbeing. For example, in a problematic situation emotions are strongly present when trying to improve one's situation. This is what happens, for instance, when one tries to control the negative emotional reactions by directing them elsewhere or when one tries to handle the situation by self-control (see also Goetz, 2005). 
Brenner and Salovey (1997) consider the concept of emotional regulation as a subconcept for emotional coping. According to the authors, both emotional coping and emotional regulation are processes with which for example difficult problem situations are handled. Previously learned strategies are used in both processes in order to manage the situation. Individuals store emotional regulation processes they have used in their repertoire, as Boekaerts (1996) asserts. This repertoire is an important part of the emotional coping process and from it an individual can activate possible forms of emotional regulation in suitable situations after an emotional coping process has started. Eisenberg has studied emotional regulation with a variety of research groups (see Spinrad et al. 2006; Hanish et al. 2004; Eisenberg et al. 2004; Eisenberg \& Spinrad 2004; Spinrad et al. 2004) and has noted that the definitions of emotional regulation are clearly connected to Boekaerts's (1996) model of the coping process, which forms the theoretical basis in this article for understanding the phenomenon of emotional coping. According to Eisenberg's research group (2000), emotional coping is a process that consists of conducting, sustaining, confirming, and consolidating inner emotional states. Furthermore, it is an emotional-based psychological process that helps to achieve the goal of the process of emotional regulation. One area in this model is the learned systems that comprise of the individual's repertoire of emotional regulation (see above). For this reason, emotional regulation and coping are seen as firmly interconnected. This was also the rationale for using the model of emotional coping created by Eisenberg's research group (1993) as the basis for the empirical execution of the research (see Research Method).

Emotional coping can also be approached from the perspectives of emotional intelligence and emotional regulation. Zeidner et al. (2003) consider emotional intelligence as a positive temperament, learned skills, and self-conscious emotional regulation. These factors together form emotional intelligence and show a connection to genetic heredity. The authors (2003) define emotional intelligence as the ability to understand, perceive, regulate, and work the emotions by adjusting them to the self and others. They think that emotional intelligence includes, among other things, control of the mind and empathy. The most famous American researcher of emotional intelligence, Goleman (1995) is of the opinion that it consists of self-consciousness, self-control, motivation, empathy, and social skills. Emotional coping is fundamentally a process of restoring wellbeing which is affected by a child's temperament on which individual differences in reacting and coping are based. An individual's genetic heritage is also connected with the process of emotional coping because the ability to react is seen as being connected with the genotype. Therefore, it could also be considered as temperamental reacting (Fox, 2003). 
As the previous definitions show, the concept of emotional coping is ambiguous. For instance, Zeidner et al. (2003) think that the sub-concepts of emotional intelligence are so broad and non-specific that it is hard to operationalize them in a distinct way. Therefore, their intention has been to show that emotional intelligence can be seen as behavior that epitomizes empathy and cognitions. Mayer and Casey (2000) define emotional intelligence as a resource for efficient processing of emotional information. This processing consists of observations, assimilation, comprehension, and emotional coping.

\section{The development of emotional coping}

Zeidner's research group (2003) has constructed an integrated model for the development of emotional intelligence where emotional coping is considered intertwined with temperament and previously learned skills. They think that a child's emotional intelligence develops through feedback, modeling, and reinforcement, for example in interaction between a mother and a child. Later on when a child gets older, the interactions involve more and more people, such as the child's friends, teachers, and other adults. Based on Zeidner's model, it can be assumed that a child's emotional coping develops, among other things, in an interaction with social factors such as the parents, friends, and teachers (Zeidner et al., 2003). According to the researchers, emotional coping not only includes social skills but is also interconnected with social skills. Similarly, other studies (Sahlberg \& Leppilampi, 1994, p. 83; Sharan \& Sahlberg, 2002, p. 402; Androjna et al., 2000; Krantz et al., 2003; Siegel, 2005; Krol et al., 2004) have pointed out that the social skills of pupils in all age groups (Jordan \& Le Metais, 1997) can be developed with interactional teaching methods.

On the other hand, the development of emotional coping is an individual's inner process that can be dissected by Boekaerts's (1996) model of the coping process. According to the model, an individual builds on emotions and assesses their selection of methods and strategies in a problem or stress situation. According to Boekaerts (1996), in a problem situation an individual uses emotions, various behavior-related reasons, and the field of cognitive coping strategies for directing or restoring their wellbeing and turning the current situation into a better one. This process involves an individual's assessment, intentions, and strategies. Boekaerts (1996) writes about two functions of coping defined by other researchers (see Lazarus, 1985; Goetz, 2005) that are problem-focused coping and emotion-focused coping. The first one focuses on the problem itself and the latter on emotional regulation trying to regulate the negative emotional reactions for example with alienation or self-control. 
Based on the model of coping process, Boekaerts (1995) has introduced a model of controlled learning process in which a central factor is also represented by assessment functioning as a mechanism for the process of attracting attention and channeling energy. Both models, the model of coping processes and the model of the controlled learning process, are about finding a controlled balance. According to Boekaerts's model of the controlled learning process, learning activities such as various problem solving tasks trigger a special kind of activity because the learning activities affect, among other things, pupils' personal effort and sensitivity (Boekaerts, 1995). If a learning activity is considered as positive, the prevailing assessment in that situation will lead to strong learning intentions and to a level of positive experience that activates the functional ways of coping and learning; whereas a prevailing unfavorable assessment results in poor learning intention and a negative experiential level. The latter "path" does not lead to learning (Boekaerts, 1995).

The classification of emotional coping by Eisenberg's research group (1993) formed a basis for the observation and description of this phenomenon in this research. The classification of Eisenberg's research group consists of three main categories for emotional coping with 13 sub-categories altogether:

A. Constructive coping: 1) Instrumental coping, 2) Emotional intervention, 3) Instrumental aggression, 4) Avoidance, and 5) Distraction;

B. Emotional venting: 6) Venting, 7) Emotional aggression, 8) Cognitive restructuring, and 9) Emotional support;

C. Passive coping: 10) Cognitive avoidance, 11) Instrumental intervention, 12) Instrumental support, 13) Denial.

To sum up, emotional coping can be understood as emotional intelligence intertwining with temperament and previously learned skills (Zeidner, 2003) and as an individual's inner process where coping is based on emotions and behavior-related reasons (Boekarts, 1996) and where coping has both problem-focused and emotionfocused functions. Furthermore, Eisenberg's research group (1993) has illustrated even a more detailed definition of emotional coping which is utilized in this research as well. Based on the above-mentioned findings about the connection between learning activities and positive emotions, it seemed reasonable to examine how coping processes can be enhanced by various learning activities. Therefore, the aim of this article is to answer the following two research questions: 1) How does emotional coping develop in primary school pupils? 2) With what kind of teaching methods can primary school pupils' emotional coping be enhanced in interactional learning situations in a classroom? 


\section{Method}

Design

The study was carried out as an action research with first-grade pupils at a primary school. During the research, a range of interactive learning activities were planned and carried out in the classroom, measures of emotional coping were created, and ultimately, nine pupils were selected as research participants. The research material was collected by observing interactive learning situations and through the use of self-assessment forms. Self-assessment forms were considered suitable because, school aged children (in Finland, children go to school in the year in which they turn seven) achieve the ability to understand themselves as social beings and use this information when controlling their self-regulation. Zeidner et al. (2003) stated that among children, aged between six and eight, this can be considered as the conscious development of metacognitive self-regulation that turns from understanding and regulation in the flow of consciousness into awareness of a specific cognitive process. According to Saarni (2000), a child is normally capable of self-assessment when starting school which is a prerequisite for the ability to regulate or control the self in relation with others' presumptions of appropriate behavior.

The researchers developed the self-assessment form by themselves. In order to increase the validity and reliability of the questionnaire, the questions in the selfassessment form in this research were designed so that first-graders would find them easy to answer. The self-assessment forms consisted of direct questions (see Tomal, 2003, p. 50) with multiple choices and were based on the classification of emotional regulation described earlier (Eisenberg, et al., 1993). A scale of facial expressions was used as the multiple choices in the self-assessment form because it is commonly used in young children's self-assessment forms and text books at school. In this research, the scale of faces was used above two possible answers having either a smiley face (the corners of the mouth facing upwards) or a sad face (the corners of the mouth facing downwards). The former would illustrate the choice "I agree" whereas the latter "I disagree". It was also explained to the pupils every time they were to answer the questions. The intended function for the pictures was to make pupils' answering easier because not all of the pupils were able to read in the fall semester of the first grade.

Despite the careful design of the self-assessment form, the researcher read out all questions to the pupils calmly before the pupils chose the suitable answers. Questions were read out again twice, one by one. After reading them out, two rows 
were marked on the blackboard above which the choices "I agree" and "I disagree" were written. The previously mentioned facial expressions were drawn above the text in order to illustrate the text. Tomal (2003, p. 57-58) notes that one of the most challenging situations in designing a questionnaire is the one when working with young children. Then, there is always a possibility that children's abilities to read and understand vary. Young children may find it difficult to understand the scale that is used in the questionnaire. Therefore, a practical scale is one with facial expressions because when working with children it is a good strategy to read out the questions and ask children to choose a suitable face that illustrates their answers. For example, children had to answer to the question "I solved the task alone" and select a suitable answer for that statement from the scale of facial expressions.

In this research, the self-assessment forms were used for measuring the pupils' emotional coping and to support not only the researcher's observations concerning their development but also the selection of the participants for the research (described in greater detail in section on Data and Evidence). The reliability of the selection was supported by the fact that after several self-assessments, pupils had learned the answering technique. However, this can also be seen as decreasing the reliability because, for example Tomal (2003, p. 84) points out that pupils can become "test-intelligent". Being aware of this kind of phenomena, the researchers' interpretations did not lean solely on the pupils' self-assessments but also on the background information and observations. Nevertheless, the information gathered by self-assessments was valuable and supported the researchers' interpretations.

During the research period, there were 18 learning situations, in which pupils solved math problems and played math games in groups of two or three. The teaching methods used in these learning situations were streaming and reflective tasks. Therefore, the question is about interactional teaching methods which in this research meant that the pupils worked in the learning situations in groups of two or three. Interactional teaching methods consisted of mathematical problem solving tasks and games. The pupils' emotional coping was developed within the interactional tasks by a variety of subtasks as well as pairing and group arrangements. The tasks included first-graders' basic mathematical problems as well as subtasks that required reasoning.

Streaming refers to the reflective tasks that encouraged the pupils to reasoning and reflection. Part of both the tasks and games were selected from the first-grade math teacher editions, text books, and supplementary material. Part of the tasks was modeled and made suitable for pupils. Some of the tasks were created by the researcher, who also was the teacher of the class. In the mathematical problem- 
solving and reasoning tasks for example, pupils had to fill a proper number in a triangle or chart. In addition, tasks were used in this research where pupils had to create certain figures of, for instance, tangram peaces or sticks (a task could be about how many similar figures one could create from the sticks in a picture). In some tasks, pupils had to draw a figure in the last empty box. The game situations in the research followed the traditional course of a game. Pupils rolled a dice in turn and solved certain math tasks during the game. Sometimes, a player had to wait for one extra-round for their turn. Pupils also played a game where they had to insert the number of a dice into the pictures shaped like a heart so that the sum of a number in the heart and in a dice would be ten. Pupils always colored the heart they had finished and in the end, the winner was the one with most colored hearts.

The vision of change and reflection

Emotional coping that exemplified six of the categories in the classification of emotional coping by Eisenberg's research group (1993) introduced earlier was found in the observations in this research: instrumental coping, avoidance, venting, emotional aggression, emotional support, and cognitive avoidance. These concepts can be explicated briefly in the following way: Instrumental coping manifests itself in practice so that in a problem-solving situation the pupil tries to solve the tasks by working alone and ignoring other pupils. Avoidance as constructive coping means that a pupil sits by in a learning situation and does not concentrate on solving the problems. Venting in a problem solving situation means literally getting excited by the task, whereas emotional support represents struggling together to solve the problem. Emotional aggression refers to sulking and speechlessness. Cognitive avoidance as passive coping in a problem situation means that a pupil quits in the middle of a task. This article focuses on these forms of emotional coping in the math lessons.

The research was an action research that, according to Mills (2007), starts with a vision of change and thus differs from the traditional research paradigm because an action research wants to enhance positive change. Therefore, a research situation can never be seen as value neutral. In addition, action researchers direct their action in a moral and socially justified way. Action researchers are not satisfied with just reporting their conclusions. The change is based on the researchers' findings and it prerequisites looking at the action both from inside and outside in order to see what actually happens during the action. When the action aims at a conscious change, a research that is planned to enforce it has to be reflected from several perspectives (McNiff \& Whitehead, 2005, p. 3; Somekh, 2006, p. 6-7.) 
Reflection is an important part in pursuing change. Schmuck (2006) points out that action research teaches a researcher reflective reasoning and understanding to face various situations as well as prepares a researcher to act in a new way. By reflection, a researcher demonstrates their own action, maturation, and values, and considers them through the change (see Schmuck 2006, p. 10). The high-level reflectivity and sensibility that belong to a researcher's role are factors through which the whole process of an action research progresses. Researchers can understand themselves in a better way by the interactional, inner reasoning. A researcher's professional and reasoning nets together mould his or her identity (Somekh, 2006, pp. 6-7).

Proactive action research

The research method in this article focuses on the practical research purposes that are also emphasized in American and English approaches to action research. The English pragmatism prefers concepts such as teacher study or classroom study (Heikkinen et al., 2006). McNiff and Whitehead (2005, p. 4) note that an action research is a practical and systematic form of research that is based on the happenings of everyday life. According to Stringer (2004, p. 2-3), action research has a practical base and its results are direct and efficient in its context.

Schmuck (2006, p. 31) has presented two models for action research. The first model is a Proactive Action Research and the other one is an easily reacting, Responsive Action Research. These models differ from each other in the research cycle at the last phases of research. In the proactive action research, action precedes research; as it did in the research presented in this article. The researcher-teacher worked first with the pupils, observed their reactions to the situation and in the situation, after which the nature of the action as well as the occurring development needs were studied (Schmuck, 2006, p. 31).

Participants

One of the main goals for this research was to enhance pupils' emotional coping to develop into emotional directedness (see Eisenberg et al., 1993; Blair et al., 2004), when a pupil is able to disentangle his/her emotions in a problem situation by discussing the problem with a class mate, working together, as well as struggling together to solve the problem and accomplishing the tasks. For this reason, it was not adequate for the main goal of the research to select pupils who already were capable of working in an interactional manner. Instead, nine pupils $(3$ girls and 6 boys) from the class ( $N=21$ pupils) who had difficulties in interacting with their class 
mates (based on the self-evaluations and observations) were selected to participate in this research. With this number of pupils, it was possible to carry out the observation required by the research design. The empirical selection was grounded in the idea that the researcher should be selective and should select for example two or three participants who represent the core of the phenomenon and whom the researcher would observe (McNiff \& Whitehead 2005, p. 63).

Every student selected in this research got a new name with the first letter representing the level of their emotional coping. This level (see Eisenberg et al., 1993) was defined based on the self-evaluations ( 6 pupils) and observations (3 pupils). Six pupils of the nine who participated in the research were selected based on the results from self-assessment form (see Research Method). The selection was not made immediately based on the first learning situation because the researcher did not trust the pupils' self-assessment yet (although, pupils should be capable of accurate self-assessment as mentioned previously). From the self-assessment form, the choice "I solved the task alone" was studied because it illustrates instrumental emotional coping that cannot be observed as interactional action in the research. Pupils' final choice was not decided until after several self-assessments in order to guarantee as reliable selection for the group of pupils in the research as possible.

Three of the nine pupils who participated in this research were selected based on the researcher's observations that were grounded in the pupils' background information and her familiarity with the pupils. Based on this, the stage of emotional coping was defined as well. At the beginning of the research, the classification of emotional coping was based on Eisenberg's research group's model introduced previously. The researcher gave the pupils new names derived either from the category or subcategory of emotional coping. Pupils presented only four categories of emotional coping because the researcher did not find pupils who would have typified all categories of emotional coping in Eisenberg's model. Thus, the pupils were called (the level of the emotional coping in the parentheses): Isabelle, Ike, Irene, Ian, Ivan (Instrumental coping), Connor (Cognitive avoidance as passive coping,), Aaron, Aidan (Avoidance as constructive coping), Eric (Emotional aggression).

Procedure

Observation

When a researcher wants to guarantee the validity of the research method, he/she should use between two and four of the basic methods that are questionnaire, 
interviews, observation, and documentation in order to measure every variable during the research; in other words, through triangulation of sources (Schmuck 2006, p. 54). In this research, the data was collected with the help of observation and selfevaluation forms.

The observation method used in this research was direct observation because it had the advantage of the researcher being able to acquire first-hand information. It enabled the researcher to collect the data in a real-life situation (Tomal, 2003, p. 29). The learning situations were observed so that the researcher who was simultaneously the pupils' teacher wrote down the pupils' talk as such. According to Tomal (2003, p. 30), direct observation is practical because it can be transferred into anecdotal form. When writing down these anecdotal notes in a classroom situation, the key factor is the prompt observation of the important behavior that is relevant to the research. Because in the learning situation the researcher was also the teacher in the class, she sometimes had to leave an interesting conversation the pupils had in order to advise other pupils who needed help. The researcher was an attentive participant in the learning situations, because the pupils needed her specifically as their own teacher. Schmuck (2006, p. 50) refers to an attentive observer with a concept of observant participation (vigilant, intent participation). Still, the researcher tried to control the situation so that she would return to observe the interesting situation as soon as possible. After a lesson, the researcher revised the notes in the observation diary so that they would be clear and easy to analyze later on. The researcher looked through the notes always during the same day they were written down when the researcher still had them fresh in her mind.

The data analysis was done by constructing a chart of the observation notes adapting Tomal's (2003, p. 32) anecdotal observation method. In practice, this meant that the pupils' talk and behavior were documented in the form of a table. The table consisted of four columns: date, pupil's name, citation from the observation diary, and the researcher's comments on the observations. This is how the researcher operationalized the concepts of emotional coping. The researcher's comments were significant for the research because the classification of the emotional coping was made based on these in order to know in which direction and how the emotional coping had to be developed. The column would have comments such as: -wants to do together, -discusses the task with a partner, - asks for advice. These observations of the learning situation, the researcher's precomprehension, and the classification for the emotional coping by Eisenberg's research group (1993), formed the basis for developing the pupils' emotional coping. 
Self-evaluation

In this research, a self-evaluation form was created based on the previously mentioned classification by Eisenberg's research group. The tasks that were related to the questions in the evaluation form were designed so that the first-grade pupils would find it easy to answer. According to Tomal (2003, p. 50), the main function of the questions is to ask directly in order to acquire information for the later analysis with which the plans of action can be developed. The questions allowed pupils to choose between two answers the most suitable one (I agree or I disagree). Tomal (2003, p. 56) says that closed-ended questions, allowing the respondent to choose between a variety of answers, are designed to measure respondent's opinions, knowledge, or conceptions.

Two kinds of self-evaluation forms were used in this research. After a mathematical problem-solving situation, the pupils had to answer the following nine questions: 1. I did the tasks together with my friend, 2. I solved the task by myself, 3. I tried to solve the tasks by myself when they seemed difficult, 4 . We tried to solve the tasks together when they seemed difficult, 5. I concentrated well on doing the tasks, 6. I found the tasks pleasant, 7. I completed the tasks by myself, 8. We completed the tasks together, 9. I quitted doing the tasks. Of these questions, numbers 2, 3, 7, and 5 (a negative answer to the question no 5) were planned to measure the constructive coping; the questions number 1, 4, 8, and 6 emotional venting; and the question number 9 (a negative answer) passive coping. The pupils answered the second selfevaluation form after a game situation. The questions were the following: 1. I did the tasks together with my friend, 2. I solved the task by myself, 3. I concentrated well on doing the tasks, 4. I found the tasks pleasant, 5. After losing a game, l'll get angry or start to sulk. Of these questions, numbers 2 and 3 (negative answer in the question no 3) measured constructive coping, numbers 1 and 4 emotional venting, and number 5 emotional aggression.

The learning situations

The goal for developing emotional coping in this research was emotional diversion that according to Eisenberg et al. (1993, 1422-1423) means that a pupil talks about his/her problem with a friend or a teacher hoping that he/she will get advice. Therefore, in this research, emotional diversion relates to such behavior where a pupil could direct his/her emotions in doing together, asking for help from a friend in a problematic situation, trying to solve the problems together, as well as completing the tasks together. 
The mathematical problem-solving / reasoning tasks that took place at the beginning of the research in September 2006 (4 learning situations) were based on figures where pupils had to divide the figures into two or four pieces and arrange three figures into various possible combinations. Between October and December in 2006, two learning situations took place in which pupils were supposed to do addition tasks within a chart or a triangle, add numbers in a sequence of numbers, split figures equally, and create various animal figures of tangram pieces. Three learning situations took place in January 2007, four in February, and one in March. The tasks in these situations were stick tasks (they had to form figures with sticks), tasks that were based on dividing numbers, completing the sequences of figures, and counting the number of cubes in cubic formations.

In the fall semester in 2006, we had two mathematical game situations. In the first one, pupils played two different games and in the second situation, the purpose of the game was not to win. Two game situations took place in the spring 2007 as well. The purpose of these games was to reach the goal first. In all game situations, pupils used a dice and counters as playing tools.

Results: How did the emotional coping develop?

Next, the development of the pupils' emotional coping is described in the way in which it appeared during the research process.

The development of instrumental coping

- Mathematical problem solving and reasoning tasks

The research focused on pupils' mutual interaction as it forms the basis for the development of emotional coping. The goal of the research process also rested on this interaction: how to find such interactional teaching methods that support and enhance the development of emotional coping.

After the first learning situations observed in September, the participants' emotional coping strongly typified instrumental coping lacking the interaction with others although the tasks were designed in a way that the pupils could be able to solve them together. Sahlberg and Berry (2003, p. 40-41) name three tasks for interactional learning: Firstly, they suggest that all members of the group should find it easy to participate in doing the task in the interactional learning situation. Secondly, every 
pupil must have the possibility to talk, and thirdly, to make choices and decisions in the group.

The first signs of the development of instrumental coping appeared in the learning situation in October (13 Oct 2006: problem-solving/reasoning task) when lke tried to take turns with his partner. This development occurred as he asked his partner: "Let's do this in half [split the task]". The next time when development in instrumental coping was recognized in a learning situation (14 Nov 2006), the pairs and groups shared tangram pieces of which they had to construct figures similar to the given model. Ivan's, Connor's, Eric's, and Isabelle's emotional coping had developed and they asked the other pupils in the group for advice and tried to construct the figures together.

The next learning situation in January (16 Jan 2007: problem-solving/reasoning task) showed that Isabelle's instrumental coping had developed into a more interactional one. At the beginning of the research, Isabelle's stage of emotional coping was categorized as instrumental coping referring to her way of solving the problemsolving tasks alone in a group situation. In the learning situation in January, Isabelle's emotional coping had changed and was seen as having developed because, in this research, we define development as a progress towards superior forms of coping: interactional emotional support. In the learning situation in January, Isabelle discussed the task with her partner in the learning situation and asked the partner for help to solve the problem. Although she sometimes did her tasks alone she commented on Irene: "Look, like this". Ivan's and Aaron's instrumental coping was to show some development on the 24th of January 2007 (problem-solving/reasoning task) when the boys started working in turns and tried to solve the problem together. The next citation from the observation diary in the 24th of January 2007 illustrates the boys' action:

Ivan - Aaron:"Put there 8 and 0" -Takes pencil from Aaron's hand and writes it down as well. - Talks to himself: "1 and 7" (writes down) -Then, starts doing in turn.

Ivan - Aaron:"What, is it 0-10?" -Writes it down after getting an accepting look from Aaron.

Ivan - Aaron:"No, I think it is 9 and 2" (corrects the partners' suggestion).

The learning situation in February (7 Feb 2007: problem-solving/reasoning task) was surprising because six of the pupils (Connor, Ivan, Aaron, Irene, and Isabelle) did not use instrumental coping. Instead, in learning situation they asked for advice to solve the task and worked together with the others. However, Irene's and Isabelle's action 
still had some features of instrumental coping. The following citation from the observation diary (13 Feb 2007: problem-solving/reasoning task) illustrates the girls' action in practice:

Isabelle - Irene: "I'll do that one".

Isabelle - Irene: "What are you supposed to do here?" -lsabelle holds back the handout all the time and fills in the boxes.

Isabelle - Irene: "How do you do this one?"- Isabelle does not listen to Irene but writes down her own answers, talks to herself, and fills in the handout by herself.

- The mathematical games

The game situation (21 Nov 2006: the goal was to win) did not enhance the pupils' instrumental coping because only Ike, Aidan, and Eric played together with a partner or with other pupils in the group. In the next game situation on the 30th of November 2006, the situation was already different, because according to the observations, all pupils who participated in the research played the game in a group. In this game situation, the goal was not to win. According to the pupils' selfevaluations, six pupils told that they played together with someone. The following citation from the observation diary (30 Nov 2006) describes the situation:

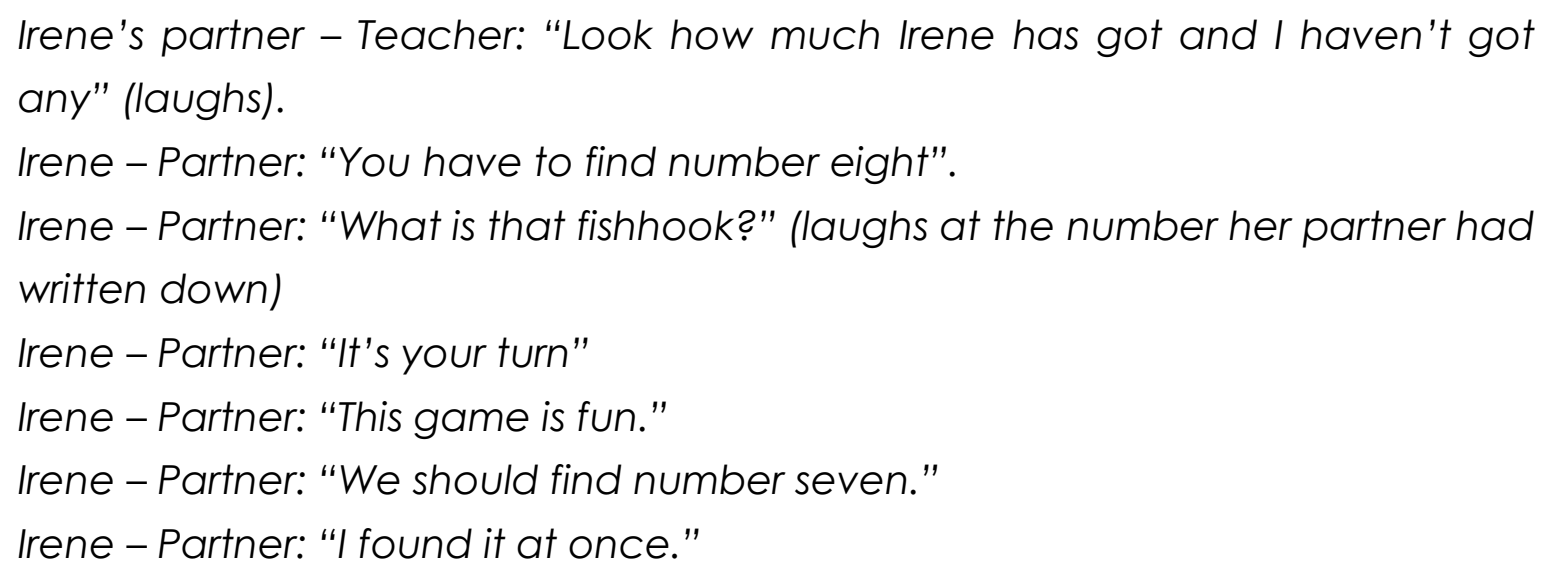

The third game situation with the goal of winning (10 Jan 2007) again showed that the instrumental coping did not appear. The summary of the observations after the game situation indicated that only Connor and lan played the game together with a partner or other pupils in the group. Although they acted in this way, their action partly represented instrumental coping because they controlled the game in a selfish manner. Ian's and Isabelle's action in the game situation exemplifies the instrumental emotional coping in that situation well (a citation from the teacher's diary, 10 Jan 2007): 
lan - Isabelle: "It's your turn." - lan shows where Isabelle should go.

lan - Isabelle: "Go there."

lan - Isabelle: "I didn't see the number you got. Throw the dice again."

lan - Isabelle: "Now, move it right there."

Ian - Teacher: "I actually won the whole game because I won three times."

\section{Avoiding a problem situation}

Avoidance means that a pupil sits by in a learning situation and does not concentrate on solving the problems. The avoidance of a problematic situation related to the pupils' constructive emotional coping was observed in the learning situation in December (11 Dec 2006: problem-solving/reasoning task). The avoidance was difficult to observe because usually it did not occur clearly in the pupils' communication or action and therefore, the avoidance of a problem situation was studied with the data collected through the pupils' self-evaluations.

One question in the self-evaluation form ("I concentrated on the task") asked that directly from the pupils. The summary of the pupils' self-evaluations from the learning situation in December showed that all the other pupils except Isabelle and Aidan had been concentrated in the learning situation. Based on this perception, it was decided to develop the pupils' skills to avoid problem situations with a game situation (21 Nov 2006, 30 Nov 2006, and 10 Jan 2007). These skills were developed by mathematical games. In the first game situation in November 2006, the pupils tried to conquer towers by addition tasks that were four in both players' game board. The one who was able to conquer the towers first was the winner. In the other game situation in November, the pupils played two different games. The first game was the following: How gets to the school first as you can go forward at one time equal amount of steps as is the number in the dice? The one who gets to school first is the winner. The other game involved heart figures; each of which had some number in it. The pupils' task was to roll the dice and complete the hearts with numbers so that the sum in a heart equaled ten. Some of the pupils completed the hearts in turn without competing whereas some of them marked their numbers with different colors and thus, they could find out who won the game. According to the research, the mathematical game situation enhanced the pupils' emotional coping when the purpose of the game was not to win. The development appeared so that every pair of pupils or a group played the game together. Eight of the pupils reported in the self-evaluation form after the game situation in January 2007 (10 Jan 2007) that they had concentrated. Only Aidan thought that he had not concentrated on the game. 
Venting

- The mathematical problem-solving and reasoning tasks

The summary of the pupils' self-evaluations in the learning situation in December 2006 (11 Dec 2006: problem-solving/reasoning task) showed that the pupils frequently used venting when disentangling their emotions. In this research, the concept of getting excited by the task referred to venting. However, Aaron and Aidan were not excited in the learning situation. Although in the second learning situation in February (13 Feb 2007: problem-solving/reasoning task) the teacher tried to provide the pupils with tasks that would inspire them she did not succeed entirely because according to Aidan's self-evaluation he did not get excited in this learning situation; neither did lan at that time. On the other hand, a citation from the observation diary proves that Aidan was enthusiastic in that learning situation (13 Feb 2007):

Aidan - Partner: "What are you doing?" (Puts the pieces following the partner's directions)

Aidan - Partner: "Look how small" (laughs)

Aidan - Partner: "Alright. Put a triangle there." (They work the task adding the figures in the empty boxes in turn)

Aidan - Partner: "I mean here."

Aidan - Partner: "We have to color these here but it will be alright".

Aidan - Partner: "Something should be left there." (laughs and taps his partner's hair with a pen)

Aidan - Partner: "Alright, four."

Aidan - Partner: "There, (laughs) now it's your turn."

Aidan - Partner: "Put a triangle there."

- The mathematical games

In the game situation in November 2006 (30 Nov 2006) Ike, Aidan, Irene, and Eric used venting according to the observations. One question in the self-evaluation ("I found the task pleasant") illustrated the pupils' enthusiasm. The result from the summary of the self-evaluations showed that Isabelle, Connor, Ike, Irene, Ivan, and Eric were excited. After combining the results from the observations and selfevaluations, it seemed that all the others but Aaron were excited in the situation. Getting excited of the game situation did get better because in the previous game situation (21 Nov 2006) only Irene, Aidan, and Eric were enthusiastic about it. 
When the game situation did not aim at winning (30 Nov 2006), Eric did not get inspired but expressed his boredom in the game situation. It seems that the pupils got easily excited of the things that include competing. Especially, when competing in groups, the spurring from other members of the group makes even the slowest pupils try harder and to do their best. Competition as a means for education has been explained by it teaching self-control and appropriate attitude to the pupils both in times of failure and success. On the other hand, competition, however, is an opposite of collaboration. Competing is risky when the competition gets more and more important. Then, the educational perspectives tend to be forgotten and a selfcentered behavior takes over.

The pupil-specific development

- The development of emotional directedness

Emotional directedness consists of solving the tasks together, struggling together to solve the tasks, and completing the tasks together. In a game situation, emotional directedness appeared as playing together and playing the game until it ended. Next, the development of pupils' emotional directedness is dissected individually.

Eric

Eric's action with a partner or with other pupils in the group resembled emotional directedness because he worked together with other pupils. Struggling together in order to solve the problem did not appear until the end of the research process. The development in emotional directedness showed when Eric started finishing the tasks together with his partner or group members in January 2007.

Ian

lan's emotional coping was similar to emotional directedness at the end of the research process. According to the observations, he did not try to solve the problemsolving tasks until in the third learning situation in February (20 Feb 2007: problemsolving/reasoning task). The direction of the development in emotional coping varied because sometimes his emotional coping was instrumental and occasionally it typified emotional directedness.

Isabelle

Isabelle's emotional directedness during the research process appeared together with instrumental coping. Some emotional directedness occurred in Isabelle's action in the first learning situation in March 2007 (13 Mar 2007: problem-solving/reasoning task) when she solved the problem-solving tasks in the group and completed the 
tasks together with the other pupils. However, a clear continuum of emotional directedness did not appear during the research process.

Irene

Irene's emotional coping was not instrumental coping (working alone) any longer at the end of the research but it did not turn into any deeper emotional directedness either because Irene did not try to solve the tasks together with others. Irene showed some avoidance of a problem situation starting from the learning situation on the 13th of February 2007 (problem-solving/reasoning task) when she did not participate in doing the task. A citation from the observation diary (26 Feb 2007) illustrates the situation:

Irene - Isabelle: "It is the same figure. First, an arrow up, then down" (Irene sits by Isabelle, rolling her pen sometimes and looking at the teacher) Irene - Isabelle: "So, put there..."

In the last learning situation in February (26 Feb 2007: problem-solving/reasoning task), Irene did her tasks together with other pupils; which showed some development in emotional coping.

Ike

Ike was the first of the pupils in this research whose emotional coping started to develop into emotional directedness. Finishing the tasks together with others was not continuous, but lke solved the tasks and struggled together with the others to solve the tasks constantly during January and February.

\section{Aaron and Ivan}

Ivan was a pupil who tended to avoid a problem situation at the beginning of the research by sitting by in the learning situations. He worked alone in the problemsolving and game situations during the whole fall semester. Aaron and Ivan worked in pairs for the first time in the first learning situation in 2007 (10 Jan 2007), which was a game situation. Then, according to the observations, the boys' action did not change in any way because Ivan worked alone and Aaron sat by. In the next learning situation the boys worked again in pairs and the change started to occur in their actions concerning collaboration and finishing the tasks together. In addition, they started to show progress also by struggling together to solve the tasks.

\section{Aidan}

Aidan's emotional coping was categorized as avoidance at the beginning of the research which meant that in a problem-solving situation or game situation he did 
not concentrate on the task but preferred sitting by and watching. Aidan's action depicted cognitive avoidance as well because sometimes he quitted doing the tasks. In February, his cognitive avoidance developed into emotional directedness when he completed the tasks together with other pupils. He also struggled with the others to solve tasks during January and February, if only occasionally. However, he did the tasks together with others regularly in January and February.

\section{Connor}

Connor's emotional coping featured partly emotional directedness in the second learning situation in December (14 Dec 2006: problem-solving/reasoning task), when he started to solve the tasks together with a partner or other pupils in the group. Connor's cognitive avoidance in a problem-solving situation turned into completing the tasks together. At the end of the research, his emotional coping developed into emotional directedness because he tried to solve the tasks together with a partner or a group. Struggling together with others was constant at the end of the research as was solving the tasks together.

\section{Discussion}

The study illustrated that the pupils' emotional coping developed during this action research. However, since there was not any control group, it is not sure whether the learning situations enhanced the development or not. Nevertheless, the results show that the development can be seen by means of mathematical problem-solving and reasoning tasks as well as mathematical games described in the previous sections (see Research Method). The development took place only when the game did not aim at winning. The pupils did the tasks and played games either in pairs or in groups of three. The development of emotional coping was individual and developed in stages. The emotional coping of all the nine pupils developed during the research process and eight pupils' emotional coping could be classified as emotional directedness at the end of the research process; some achieved emotional directedness earlier than others.

Would the development in emotional coping have appeared in for example the tasks related to physical education (P.E.) or art as well? At the beginning of the study, the researchers were already aware that during the P.E. lessons the pupils confront interactional problem situations constantly, so those lessons would possibly have been productive learning situations in order to develop the pupils' emotional coping. However, for a researcher who works both as a researcher and a teacher, observing the learning situations in P.E. lessons would have been impossible because 
the learning space is often considerably wider in P.E. lessons than for example the classroom that was used in this research - namely, the learning space for the mathematical learning tasks.

The reliability of the research

The observation in this research was based on an interpretation of the pupils' actions. The researcher had her own perception of the pupils' emotional coping. The pupils knew that their own teacher acted as a researcher and as a teacher in other learning situations. At first the pupils asked the teacher about what she is writing in her note book but little by little they got used it and worked in the learning situations the same way as they did in other lessons. According to Tomal (2003, p. 85), a researcher should minimize participants' awareness of the fact that they participate in a research. Therefore, the purpose was to arrange as natural environment as possible for the research in the classroom and the learning situations were like any other math lesson in the weekly timetable.

The researcher knew the pupils beforehand which may threaten the reliability of the research. If a researcher is open and honest when reporting the research data, the reliability of a research strengthens. Kvale (1996, 241-244) divides validating into professional skills, checking, and asking. Professionalism and confidence become salient when the research results reported by a researcher are evaluated. Reliability does not only cover the methods used in a research but also a researcher's honesty. Researchers' criticality is shown at the phase of data analysis when they place their own personal style of doing research and control as the means for interpretation and observation: the truthfulness of observation and interpretation has to be controlled critically.

The perception was formed based on the research data. A theory provides an action researcher with an opportunity to link the practical work with a wider context. (Schmuck 2006, p. 54; Tomal 2003, p. 83.) Were the interpretations of pupils' actions correct and reliable? Was the fact that the pupils' maturing can pose a threat to the reliability of the research taken into consideration because the elementary-school pupils mature at different pace? Was the pupils' emotional coping recognized in this research as it appeared in reality in a learning situation? Schmuck (2006, p. 54) thinks that the excellence of an action research is bound to the efficiency of the new practice and rigor of the research data. When wishing to achieve the rigor in research data, a researcher has to create his/her own mixed valid method for producing reliable data that does not contain distortion. 
The threats to the reliability of a research are those factors that affect the reliability of the data negatively. Metsämuuronen (2006, p. 200) quotes Lincoln and Guba (1985, p. 290) when claiming that the reliability of a qualitative research consists of truthfulness, adaptability, stability, and neutrality. According to Tomal (2003, p. 83), threats to reliability can be the negative factors of the method used, lack of participants during the research, noticing those pupils who are more motivated or perform better, a researcher's conscious or unconscious preference with the matters that are significant to the research, and all factors that affect the natural research setting. Because the research process took place at a school class in math lessons, the research setting was natural in every learning situation. When a pupil who participated in the research was absent, the learning situation did not take place that day, except for one time (since one of the pupils had been absent because of illness for a long time and so many scheduled learning situations would have been cancelled because of this). Thus, self-evaluations were always received from all pupils and we did not have to collect them afterwards. The evaluations of the learning situations always took place at the same time with all pupils in the class. The actual time for carrying out the learning situations varied during the research process. Half of the pupils in the class participated in a learning situation in the morning and the other half in the afternoon. This setting could affect the reliability of the research somewhat negatively because the pupils tended to be more active in the morning than in the afternoon. This factor was realized and could have been controlled by making sure that all pupils would have participated in tasks in both times. However, that was not possible in practice.

In addition, it was easier for a researcher to observe smaller group and thus she was able to write down notes about the pupils' emotional coping more carefully which, for its part, increased the reliability of the research. The validity of a qualitative research is often complex; according to Kvale (1996, p. 244), the complexity of validating qualitative research does not result from the natural weakness of the qualitative method. Instead, it might be based on the particular strength of qualitative research to describe and ask about the complexity of the social reality under research.

Did the research answer the questions set from the start? After carrying out this research process, the answer was positive; although according to Metsämuuronen (2006), the research target in an action research is situation-bound and specific, the sample is limited and thus not representative. Action research has been criticized because the results cannot be generalized. The goal setting and method in an action research have also been blamed for being unclearly defined. At the beginning of the research, the aims were decided. However, they had to be 
checked in the various phases of the research because an action research demands constant reflection; in this case, after every learning situation. Similarly, the researcher analyzed the data in a way that is typical for an action research: in tandem with the research process.

\section{Concluding remarks}

The mastery of social skills has got a significance role in the modern school and working life. The researchers have pointed out that those people who are socially skillful manage their work better (Coll et al., 2001). Developing the emotional coping in a more interactional direction is not only significant for a pupil's future wellbeing but also in a wider context. Emotional directedness is a challenge of the future because the future competences are confronting dissimilarity, working together, and developing networking skills. Globalization including the changing professions, multilingual and multi-cultural environments demands the ability to confront dissimilarity and to cooperate. A basic skill is the ability to use these means in an interactional manner. In the prevailing culture of interaction, we have to set goals both for educators and pupils as well. In practice, this means that we are creating a culture that is founded on new structures. These structures and their goals have to be parallel at every level. The traditional interactional culture at school differs too much from the demands and needs of the today's working life (Haapaniemi et al. 2003, p. 39). Before a human being can interact with others, a trust has had to be born. On the other hand, also commitment goes hand in hand with trust because when engaging an individual gives something from himself/herself and thus, trusts in others. Sharing feelings in a problem situation enables all participant to equally participate. The equal opportunities and togetherness are the foundation pillars of the school. This social and moral task of the school should not be forgotten either in the future. The importance of a school community and tolerance are emphasized in the change as well as, especially, the significance of ethical education. "Ethicality" involves for example unselfish actions. This may prerequisite a comprehensive evaluation of all operations at school because, at the end, one teacher working within in one subject is not able to do much in order to achieve these goals.

\section{References}

Androjna, E., Barr, M. E., \& Judkins, J. (2000). Improving the social skills of elementary school children. Illinois: Saint Xavier University and SkyLight Professional Development. 
Blair, K. A., Denham, S. A., Kochanoff, A., \& Whipple, B. (2004). Playing it cool: Temperament, emotion regulation, and social behaviour in preschoolers. Journal of School Psychology, 42(6), 419-443.

Boekaerts, M. (1995).The Interface between Intelligence and Personality as Determinants of Classroom Learning. In D.H. Saklofske, \& M. Zeidner (Eds.), International Handbook of Personality and Intelligence (pp. 161-183). New York: Plenum Press.

Boekaerts, M. (1996).Coping with stress in childhood and adolescence. In M. Zeidner, \& N. Endler (Eds.), Handbook of coping. Theory, research, application (pp. 452-484). New York: John Wiley \& Sons.

Brenner, E. M., \& Salovey, P. (1997). Emotion regulation during childhood: developmental, interpersonal, and individual considerations. In P. Salovey \& D.J. Sluyter (Eds.), Emotional development and emotional intelligence: educational implications (pp. 170-183). New York: BasicBooks.

Cheng, H., \& Furngam, A. (2002). Personality, peer relations, and self-confidence as predictors of happiness and loneliness. Journal of Adolescence, 25(3), 327-339.

Eisenberg, N., Fabes, R.A., Bernzweig, J., Karbon, M., Poulin, R., \& Hanish, L. (1993). The relations of emotionality and regulation to preschoolers' social skills and sociometric status. Child Development, 5(63), 1418-1438.

Eisenberg, N., Guthrie, I. K., Fabes, R., Shepard, S., Losoya, S., Murphy, B. C., Jones, S., Poulin, R., Reiser, M. (2000). Prediction of elementary school children's externalizing problem behaviors from attentional and behavioral regulation and negative emotionality. Child Development, 71 (5), 1121-1476.

Eisenberg, N., \& Spinrad, T.L. (2004). Emotion-related regulation: Sharpening the definition. Child Development, 75(2), 317-33.

Eisenberg, N., Liew. J., \& Pidada, S.U. (2004). The longitudinal relations of regulation and emotionality to quality of Indonesian children's socioemotional functioning. Dev Psychol, 40(5), 790-804.

Fox, N. A. (2003). Not quite ready to invest. Human Development, 46, 104-108.

Giffor-Smith, M.E., \& Brownell, C.A. (2003). Childhood peer relationships: social acceptance, friendships, and peer networks. Journal of Social Psychology, 41 (4), 235284. 
Goetz, T., Frenzel, A., Pekrun, R., \& Hall, N. (2005). Emotional intelligence in the context of learning and achievement. In R. Schulze \& R.D. Roberts (Eds.), Emotional intelligence. An international handbook (pp. 233-253). Cambridge, MA: Hogrefe\& Huber.

Goleman, D. (1995). Emotional intelligence. New York: Bantam Books.

Haapaniemi, H., Haapaniemi, R., Moilanen, P., Raina, L., Suojanen-Saari, T. (2003). Karttakepin kuolema. Kokemuksia vuorovaikutteisista kasvatus- ja opetusmenetelmistä. [The death of pointer. Experiences of interactional teaching methods]. Hämeenlinna: Karisto Oy.

Hanish, L.D., Eisenberg, N., Fabes, R.A., Spinrad, T.L, Ryan, P., \& Schmidt, S. (2004). The expression and regulation of negative emotions: risk factors for young children's peer victimization. DevPsychopathol, 16(2), 335-53.

Heikkinen, H.L.T., Konttinen, T., \& Häkkinen, P. (2006). Toiminnan tutkimisen suuntaukset [The trends of action research]. In H.L.T Heikkinen, E. Rovio, \& L. Syrjälä, L. (Eds.), Toiminnasta tietoon. Toimintatutkimuksen menetelmät ja lähestymistavat [From action to information. The methods and approaches of action research] (pp. 39-75).Vantaa: Dark Oy.

Jordan, D., \& Le Metais, J. (1997). Social skilling through cooperative learning. Educational Research, 39(1, 3), 3-21.

Krantz, S., McDermott, H., Schaefer, L., \&Snyder, M, A. (2003). Improving students' social skills through the use of cooperative learning strategies. Chicago: Saint Xavier University \& SkyLight.

Krol, K., Janssen, J., Veenman, S., \& van der Linden, J. (2004). Effects of a cooperative learning program on the elaborations of students working in dyads. Educational Research and Evaluation, 10(3), 205-237.

Kvale, S. (1996). An introduction to qualitative research interviewing. New York: Sage.

Lazarus, R.S. (1985). The costs and benefits of denial. In A. Monat, \& R.S. Lazarus (Eds.), Stress and coping. An anthology (pp. 154-173). New York: Columbia University Press.

LeBlanc, L.A., Sautter, R.A., \& Dore, D.J. (2006). Peer relationship problems. In M. Hersen (Ed.), Child clinical handbook of behavioral assessment Vol. II Child Assessment (pp. 377399). San Diego, CA: Elsevier. 
Lincoln, Y.S. \& Cuba, E.G. (1985). Naturalistic inquiry. California: Sage Publications.

McNiff, J., \& Whitehead, J. (2005). Action research for teachers. A practical guide. London: David Fulton Publishers.

Matthews, G., Schwean, V.L., Campbell, S. E., Saklofske, D. H., \& Mohammed, A. R. (2000). Personality, self-regulation and adaptation. A cognitive-social framework. In M. Boekaerts, P.R. Pintrich, \& M. Zeidner (Eds.), Handbook of self-regulation ( pp. 171-205 ). San Diego: Academic Press.

Mayer, J. D. \& Casey, D, C. (2000). Educational policy on emotional intelligence. Does it make sense? Educational Psychology \& Review, 12 (2), 163-183.

Mayer, J, D., \& Salovey, P. (1997). What is emotional intelligence? In P. Salovey, P. \& D.J. Sluyter (Eds.), Emotional development and emotional intelligence ( pp. 3-31 ). New York: Basic Books.

Metsämuuronen, J. (Ed.) (2006). Laadullisen tutkimuksen käsikirja [The handbook of qualitative research]. Jyväskylä: Gummerus.

Mills, G. E. (2007). Action research. A guide for the teacher researcher. New York: Pearson Education.

Peltokorpi, E.-L. (2007). Yhtä kaikki yksinäisen - Tutkimus alkuopetuksen oppilaiden emotionaalisesta hallinnasta [No child is an island-A study of emotional coping among primary pupils]. (Acta Universitasis Lapponiensis 124). Rovaniemi: University of Lapland.

Rowe, E.W., Kim, S., Baker, J., Kamphaus, R.W., \& Horne, A.H. (2010). Student personal perception of classroom climate: exploratory and confirmatory factor analyses. Educational and Psychological Measurement, 70 (5), 858-879.

Saarni, C. (2000). Emotional competence. A developmental perspective. In R. Bar-On, \& J.D. Parker (Eds.), The Handbook of emotional intelligence: Theory, development, assessment, and application at home, school and the workplace (pp. 68-91). CA: Jossey-Bass. United States of America. San Francisco.

Sahlberg, P., \& Berry. J. (2003). Small group learning in mathematics. Teachers' and pupils' ideas about groupwork in school. (Research in educational sciences 13). Turku: Painosalama Oy. 
Sahlberg, P., \& Leppilampi, A. (1994). Yksinään vai yhteisvoimin [Alone or together]. Helsinki: Yliopistopaino.

Schmuck, R. A. (2006). Practical action research for change. Thousand Oaks: Corwin Press.

Sharan, S., \& Sahlberg, P. (2002).Yhteistoiminnallisen oppimisen käsikirja [The handbook of cooperative learning]. Helsinki: WSOY.

Siegel, C. (2005). An Etnographic Inquiry of Cooperative Learning Implemantation. Journal of School Psychology, 43(3), 219-239.

Somekh, B. (2006). Action research: a methodology for change and development. Berkshire: Open University Press.

Spinrad, T. L., Eisenberg, N., Cumberland, A., Fabes, R. A., Valiente, C., Shepard, S. A., Reiser, M., Losoya, S. H., \& Guthrie, I. K. (2006). Relation of emotion-related regulation to children's social competence: a longitudinal study. Emotion, 6(3), 498-510.

Spinrad, T. L., Eisenberg, N., Harris, E., Hanish, L, Fabes, R. A., Kupanoff, K., Ringwald, S., \& Holmes, J. (2004). The relation of children's everyday nonsocial peer playbehavior to their emotionality, regulation, and social functioning. Dev Psychol., 40(1), 67-80.

Stringer, E. (2004). Action research in education. New Jersey: Merrill Prentice Hall.

Tomal, D. R. (2003). Action research for educators. Lanham, Maryland: Scarecrow Education.

Uusikylä, K. (2005). Luova koulu, rokote kouluviihtymättömyyteen. [Creative school. The vaccine to the pupils, who don't are happy at school]. In S. Karppinen, I. Ruokonen, \& K. Uusikylä (Eds.), Taidon ja taiteen luova voima. Kirjoituksia 9-12 -vuotiaiden lasten taitoja taidekasvatuksesta [The creative force of the skills and arts. Writings of skills and arts education in children's aged 9-12] (pp. 23-31). Tampere, Finland: Tammerpaino Ltd.

Woodward, L. J., \& Fergusson, D. M. (2000). Childhood peer relationship problems and later risks of educational under-achievement and unemployment. Journal of Child Psychology and Psychiatry, 41 (2), 191-201.

Zeidner, M., Matthews, G., Roberts, R. D., \& MacCann, C. (2003). Development of emotional intelligence: towards a multi-level investment model. Human Development 46, 69-96. 
Zullig, K. J., Koopman, T. M., Patton, J. M., \& Ubbes, V. A. (2010). School climate: Historical review, instrument development, and school assessment. Journal of Psychoeducational Assessment, 28(2), 139-152.

About the authors:

PhD Eeva-Liisa Peltokorpi is graduated in education from Faculty of Education, University of Lapland, Rovaniemi, Finland. She works as a Lecturer in Viikki Teacher Training School, University of Helsinki,. She is interested in researching the experiences and teaching of emotions.

E-mail: eeva-liisa.peltokorpi@helsinki.fi

PhD Kaarina Määttä, Professor of Educational Psychology, Faculty of Education, University of Lapland and Vice-rector, University of Lapland. Her latest personal research interests have focused on early education and love, attachment and social relationships during human beings' life-span, and on guidance of doctoral thesis. Her next book, which will be published in English in 2011, deals with the pedagogy of supervising doctoral theses from various perspectives.

Address for correspondence: Kaarina Määttä, University of Lapland, Faculty of Education, P.O. Box 122. 96101 Rovaniemi, Finland

E-mail: kaarina.maatta@ulapland.fi 